\title{
QUEER WOMEN OF COLOUR: THE INTERSECTION OF CULTURE AND IDENTITY
}

\author{
by Nosipo Goba*
}

\section{Introduction}

Currently we look to our Constitution for protection as legitimate citizens in our country. However, the reality is that Black Lesbians are targeted with brutal oppression in the South African townships and surrounding areas. We experience rape from gangs, rape by so-called friends, neighbours and sometimes even family members. Some of the 'curative rapes' inflicted on our bodies are reported to the police, but many other cases go unreported. At present South Africa has no anti-hatecrime legislation. Rampant hate crimes make us invisible. Coming out exposes us to the harshness of patriarchal compliance. We are also at risk when we challenge the norms of compulsory heterosexuality.

- Zanele Muholi ${ }^{1}$

Black Queer women exist in intersecting spaces of oppression; they are discriminated against because they are Black, Queer and women and are often pathologised within the African diaspora. As bell hooks [sic] brilliantly and succinctly put forward in her book, feminism is 'a movement to end sexism, sexist exploitation and oppression.' 2 In the same way that race cannot be separated from gender and vice versa, Queer rights cannot be separated from women's rights. As a black lesbian in post-apartheid South Africa, I had to consider the way in which Queer Blackness in particular troubled feminism. ${ }^{3}$ Although the concepts of identity and the desire for belonging are a shared journey

* $\quad$ Final year LLB student, University of Pretoria.

1 Presenting her exhibition Faces and phases in 2007 in the Michael Stevenson Gallery.

2 b hooks Feminism is for everybody (2000) viii.

3 Following Judith Butler who describes 'Queer' as a: 'site of collective contestations, the point of departure for a set of historical considerations and future imaginings' l acknowledge that Queer is not only a sexual orientation, but it caters to identity beyond sexual orientation as a means of critiquing social classifications. 'Queer' can be understood to mean non-normative, and as such, in this instance, it will be used as a description for sexual and gender expressions that do conform to hegemonic heteronormative and gender-normative identities. In other words, it is used as an umbrella term for Lesbian, Bisexual and Transgender women. 
for members of the LGBTQI+ ${ }^{4}$ community in many ways, this identity had to be considered because it is negotiated and navigated under conditions of exclusion, invisibility, invalidity, misunderstanding and cultural rejection. The author had great difficulty in trying to establish what could stabilise this troubling condition and was subsequently drawn to looking at Black Queer women's identity by considering their socio-politico-legal standing through an ubuntu framework. A framework that is rooted in our traditions and reflects our culture and is thus an organic social and political justice that can address and redress the systems that mean to oppress and suppress such an identity; paying attention to the connectedness and interrelatedness of African communities and the possible ethical duty to protect vulnerable members of the community and society at large.

Through the use of photographs taken by human rights activist Zanele Muholi, a self-proclaimed visual activist and feminist artist, a visual narrative of the lives of Black Lesbians in post-Apartheid South Africa taken since 2006 until present, will be created. Muholi's photographs represent Black Queer South Africans who find themselves in the precarious position of not identifying themselves within the binary and limiting restrictions of the gender-normative and heterosexual majority and as such, are a meaningful contribution to the discourses surrounding the LGBTQI+ community which often ignore or silence race, age, socio-economic standing and women's experiences. The author will attempt the complex and nuanced task of contextualising and problematising concepts surrounding Black gender and sexual identities. In this article the author offers an analysis and critique of the positionality of Black Queer women within modern identity politics in order to unpack and demonstrate the ways in which their identity and the multiple forms of oppression and violence attached to these identities need an integrated and intersectional approach that extends beyond the bounds of the law to resist and address oppressive systems of power which Western conceptions of liberation and emancipation fail to do. ${ }^{5}$

4 This acronym stands for Lesbian, Gay, Bisexual, Transgender, Queer/Questioning and Intersex and is expanded to include ' $A$ ' and ' $P$ ' respectively denoting Asexual/Aromantic and Pansexual. This however, is not a closed list as the acronym is fluid and expands with an ever-changing understanding of and interaction with identity.

5 The term intersectionality was first coined by $\mathrm{K}$ Crenshaw 'Demarginalising the intersection of race and sex: A black feminist critique of antidiscrimination doctrine, feminist theory and antiracist politics' (1989) 139 University of Chicago Legal Forum 139. 


\section{Black queer identity}

Being alive \& being a woman \& being colored is a metaphysical dilemma/ I haven't conquered yet/ do you see the point/ my spirit is too ancient to understand the separation of soul and gender/my love is too delicate to have thrown back in my face. [sic]

Ntozake Shange 6

\subsection{Identity}

'Faces and Phases' is a portrait series created between 2007 and 2014 and is a long-term project of Muholi's that she describes as:

... an insider's perspective that both commemorates and celebrates the lives of the Black Queers I have met in my journeys. Some of their stories gave me sleepless nights as I tried to process the struggles that were told to me. Many of the women I have met have been violated and I endeavoured not to exploit them further through my work. I set out to establish relationships with them based on mutual understanding of what it means to be female, Lesbian and Black today. Faces and Phases is about our histories and the struggles that we continue to face. ${ }^{7}$

The purpose of 'Faces and Phases' for Muholi is to use portraiture to present Black Queer existence and resistance through positive imagery. The photo series is an invitation to viewers to engage in existential contemplations about African Queer people and the way their racialised, classed and gendered selves are expressed in meaningful and varied ways. 'Faces and Phases' is significant for this article in that it represents the author's socio-political aim to delve into how one understands oneself to be a woman, being both Queer and Black, how one acts in accordance with such understanding and how one relates to others as a result of that understanding.

In his 1994 work, Craig Calhoun's theoretical development of identity politics starts out by referring to the work of Hannah Arendt and Charles Taylor in saying that the human condition is that we are distinct from each other and yet that distinctness can tacitly create commonality with other humans who are similarly distinct and that, to some degree, that distinctness is dependent on common recognition. ${ }^{8}$ That is to say, on a distinction between self and other. For Calhoun, the discourse of identity is distinctively modern. It is an effort to reinforce selfsameness and secure individual and categorical

6 An excerpt from the poem 'no more love poems \#4' which formed part of the 20 separate poems contained in the choreo-poem by $N$ Shange for colored girls who have considered suicide/ when the rainbow is enuf (1977) 45.

7 Culture reporter 'Faces and Phases 10' http://www.culture-review.co.za/facesand-phases-10 (accessed 24 October 2016).

8 C Calhoun Social theory and the politics of identity (1994). 
identities and the ways in which modernity have made identities problematic in the difficulty of establishing and maintaining our own identity adequately in the face of a move away from all-encompassing identity schemes. Social construction theory is useful beyond the realm of sociology and challenges an essentialist idea that identity is produced by individual will and is singular and unproblematic. Under political and possibly intellectual circumstances, feminist thinkers have claimed a fundamental and shared identity at the "risk" of essentialism. The purpose of this is to claim value for all those falling within a specific category of identity that has been devalued, repressed or delegitimised in dominant discourse through the implied invocation of essentialism. A post-structuralist approach to identity is a project to deconstruct essentialist categories of identity. ${ }^{9}$ Recognition proves to be problematic because the way we consider and constitute ourselves is shaped by dominant social discourses which can define who it is possible or appropriate or valuable to be. This understanding is important for a consideration of the categories of identity that follow.

\subsection{Gender identity}

That man over there says that women need to be helped into carriages, and lifted over ditches, and to have the best place everywhere. Nobody ever helps me into carriages, or over mud-puddles, or gives me any best place! And ain't I a woman? Look at me! Look at my arm! I have ploughed and planted, and gathered into barns, and no man could head me! And ain't I a woman? I could work as much and eat as much as a man - when I could get it - and bear the lash as well! And ain't I a woman? I have borne thirteen children and seen most of them sold off to slavery, and when I cried out with my mother's grief, none but Jesus heard me! And ain't I a woman?

Sojourner Truth ${ }^{10}$

The distinction between sex and gender find expression in the writings of Simone de Beauvoir who argues that gender is an aspect of identity that is gradually acquired through social construction. Her argument is that 'one is not born a woman, but rather becomes a woman.'11 Queer theorist Judith Butler's theories of gender elaborate on those of de Beauvoir and further suggests that the categories of 'sex' and 'gender' are constructed and need repeated performance, as a result of which, there is no natural or unnatural gendered behaviour as all

9 Calhoun (n 8 above) 1-16.

10 An excerpt from her speech “Ain't I a woman” delivered in 1851 at the Women's Convention in Ohio.

11 De Beauvoir rejects the claim that anatomy is destiny in $\mathrm{S}$ de Beauvoir The second sex (1949) 46. 
gender is by definition unnatural ${ }^{12}$ thus heterosexuality is not natural and homosexuality is not deviant.

Toril Moi makes her stance on femininity and femaleness abundantly clear. She approaches 'femaleness' as a biological matter and 'femininity' as a set of culturally defined characteristics. ${ }^{13}$ 'Masculine' and 'feminine' are social constructs, that is to say, they are sexual and behavioural patterns imposed on bodies by cultural and social norms. 'Female' and 'male' on the other hand should only be referred to when dealing with the biological aspects of sexual difference. Thus in the on-going nature versus nurture debate, 'feminine' represents nurture and 'female' represents nature. This approach aligns itself with de Beauvoir's stance. It can be said that one of the ways patriarchy operates and maintains its power is through subjecting biological women to strict standards of femininity to reinforce the belief that these imposed standards are natural. The result of this is that women who resist against and reject these standards are seen as unfeminine and unnatural. The insistence of patriarchy that femininity is constitutive of femaleness is what needs to be resisted because not all women are female and being biologically female does not necessarily mean they will also be feminine. ${ }^{14}$

The essential or universal woman Western feminism conjures up, is oppressive to all the women who, because of race, class and sexual orientation etc., do not meet these standards of femininity because they are not protected and are then left vulnerable to patriarchal dictatorship of their bodies. ${ }^{15}$ Feminism requires a non-essentialist theory of human sexuality and desire to achieve an understanding of the power relations between the sexes. ${ }^{16}$

12 Butler puts forward the idea of identity as free-floating and connected to a performance in J Butler Gender trouble: Feminism and the subversion of identity (1990) 25.

13 T Moi The feminist reader: Essays on gender and the politics of literary criticism (1989) 117.

14 The social meaning of gender for Mackinnon is created by the sexual objectification of women as stated in her book C Mackinnon Toward a feminist theory of state (1989) 113.

15 Moi (n 13 above) 122-124.

16 Moi (n 13 above) 131. 


\subsection{Racial identity}

Black women were rarely among those Blacks and females who gained access to literary and other acknowledged forms of artistic expression, this Black female bonding and Black woman-identification has often been hidden and unrecorded except in the individual lives of Black women through our own memories of our particular Black female tradition.

Loraine Bethel ${ }^{17}$

An individual's unique relationship to a racial identity can be conceptualised through the four parameters set out by Vetta SandersThompson in her essay 'The complexity of African American racial identification,' that combine to construct a multidimensional cohesive racial identity although they can operate to the exclusion of each other. Sanders-Thompson separates racial identity into four parameters: physical, cultural, psychological, and socio-political. The physical identity parameter refers to a person's degree of acceptance of the physical attributes of Black people. The cultural identity parameter refers to a person's knowledge of the contribution Black people have made to society. The psychological identity parameter refers to a person's concern for, commitment to and pride in their identified racial group. Lastly, the socio-political identity parameter investigates a person's views and stance on the social, economic and political issues affecting Black people. ${ }^{18}$ As stated, these parameters can be present all together or separately. Harris, however, warns against 'racial essentialism' which she considers the belief in a solidly uniform 'Black experience'. For Harris, the Black woman will never be more than the losing end of a hierarchy of oppressions or the intersection of two kinds of domination if theories and dominant culture actively pursue a conceptual racial essence.

Race as an aspect of identity leads me to Black feminist writers such as Crenshaw who coined the phrase intersectionality, which can be understood to mean the simultaneous experience of multiple oppressions experienced by Black women as a single synthesised experience $;^{19}$ and Patricia Hill Collins who says that the intersecting oppressions of race, gender and class create contradictions about Black women that can lead to internalised oppression because Black women have been forced to act outside of gendered behaviour. ${ }^{20}$

17 Black Lesbian/feminist critic Lorraine Bethel in her essay writing on Zora Neale Hurston - L Bethel This infinity of conscious pain: Zora Neale Hurston and the black female literary tradition (1982) 179.

18 V Sanders-Thompson 'The complexity of African American racial identification' (2001) 32 Journal of Black Studies 158.

19 Crenshaw (n 5 above) 139.

$20 \mathrm{P} \mathrm{H}$ Collins Black feminist thought: Knowledge, consciousness and politics of empowerment (2001) 11-12 where a matrix of domination is described. 
Culture is a way in which race and gender are produced and performed as part of identity and power in a post-colonial and postapartheid context. Culture produces and regulates what one does and how one understands oneself and thus serves as a well from which one draws understandings and performances of what it means to be a woman and how women are positioned. ${ }^{21}$ The idea that Africans share a sexual culture distinct from the rest of the world is one of the ways colonial and apartheid homophobia are reproduced through the belief that homosexuality is un-African. ${ }^{22}$ Cultural narratives are part of the construction and enforcement of social roles and thus play a role in defining and limiting the way rights are exercised and enforced, even when those rights are recognised by the law.

\subsection{Political usefulness of claiming queer identity}

Those of us who stand outside the circle of this society's definition of acceptable women; those of us who have been forged in the crucibles of difference - those of us who are poor, who are Lesbians, who are Black, who are older - know that survival is not an academic skill. It is learning how to take our differences and make them strengths. For the master's tools will never dismantle the master's house. They may allow us temporarily to beat him at his own game, but they will never enable us to bring about genuine change. And this fact is only threatening to those women who still define the master's house as their only source of support.

Audrey Lorde 23

Calhoun argues that the political structure of heterosexuality is conceptually different from that of patriarchy in that, although they are intertwined, smashing patriarchy will not necessarily smash heterosexual dominance. The result being that dismantling gender subordination will not benefit Queer women and cisgender heterosexual women equally or in the same manner. ${ }^{24}$ The political structure that most acutely oppresses Queer women is heterosexuality, while for cisgender heterosexual women it is patriarchy. Within a patriarchal society 'woman' has been constructed as the 'Other' and the inferior in relation to 'man' creating a state of 'woman' being equated with subordination to man. ${ }^{25}$ The feminist's experience of the category 'woman' is the experience of being a woman in a classist, racist, male dominant

21 J Clark 'Looking back and moving forward’ (2006) 68 Agenda: Empowering women for gender equality 8 .

22 H Gunkel Cultural politics of female sexuality in South Africa (2010) 28.

23 A Lorde Sister outsider: Essays and speeches (1984) 2.

24 C Calhoun 'Separating lesbian theory from feminist theory' (1994) 104 Ethics 562.

25 Calhoun (n 24 above) 565. 
society, which imposes ideals of what it means to be a woman that she rejects. She thus does not reject being a woman, rather she rejects being the kind of woman that a racist, classist, patriarchal society expects her to be. ${ }^{26}$

Cisgender heterosexual society creates and maintains the false impression of 'natural' gender identities by prescribing alternative gender performances. Butch Lesbians enact those same prescribed performances by performing masculinity and the desire for women through their intelligibly female bodies. The mere fact that masculinity exists outside of and apart from male bodies serves to challenge the naturalness of the categories 'man' and 'woman' and begs the question why Queer women share a subordinate and deviant status. In the absence of natural gender identities, it cannot reasonably be justified that Queer women are considered unnatural and deviant beings or why a heterosexual configuration of sexuality, romantic love, marriage and the family unit are seen as authentic and aspirational. The result is that the categories 'man' and 'woman' can be deconstructed and reconstructed to include multiple categories. ${ }^{27}$

\section{The western marginalisation of black queer identity}

To be vocal, to be recognised, to be respected, to be included, because there is no way to deal with your issues without you being there. To make sure that there is a voice for your particular community. You cannot expect people to deal with your problems if you are not present and say: 'these are my issues, I need your support.

Zanele Muholi ${ }^{28}$

An important enquiry for the author at this stage is in what ways have liberal movements and socio-politico-legal systems marginalised and even excluded the identity of Black Queer women. 'Isibonelo/ Evidence' is Muholi's most comprehensive museum exhibition to date and features many of her on-going projects. It includes the captured lived experiences of living in a country where, despite constitutional protection, Queer people are not protected from targeted violence and systemic exclusion.

26 As above.

27 Calhoun (n 24 above) 571.

28 Movimientos 'Art and activism: Interview with Zanele Muholi' http:// movimientos.org/es/dss/show_text.php3\%3Fkey\%3D6355 (accessed 19 October 2016). 


\subsection{Institutionalised heterosexuality}

... these weddings have a lot to do with masculinities and gender binaries: there is a bride and a groom. I noticed that with most of the same-sex marriages that I hardly see femme and femme getting married or butch and butch. The butchness and femininity is so well-defined and pronounced. It is gender within gender.

Zanele Muholi ${ }^{29}$

Van Zyl posits that, in order to understand social justice and equality, one must understand belonging as a measure of socio-political exclusions and as the social and psychological aspects of rights. Belonging can thus be the historical and social starting point in the method of inquiry into the cultural tensions of the claims that marriage is essentially heterosexual and thus 'homosexuality is unAfrican.' 30

The constitutional prohibition of discrimination on the grounds of sexual orientation and the legal recognition of same-sex civil unions and domestic partnerships does not give Queer women authentic socio-politico-legal standing. The creation of the Civil Union Act serves to reaffirm that Lesbian and Gay unions do not fall within marriage law. ${ }^{31}$ Jaco Bernard-Naudé considers the impact of the Civil Union Act on sexual minority freedom in South Africa through the Constitutional Court's decision in the Minister of Home Affairs $v$ Fourie case. ${ }^{32}$ The Constitutional Court's jurisprudence on sexual minority freedom has always placed great value on the concepts of human dignity and equality, which is why the common law definition of 'marriage' which excluded same-sex couples as well as the Marriage Act, ${ }^{33}$ to the extent that it relied on that definition, were declared unconstitutional and Parliament was given one year to remedy the defect. ${ }^{34}$ Parliament duly responded to the Constitutional Court's decision with the first draft of the Civil Union Bill. ${ }^{35}$ The Bill provided for 'civil partnership' and not 'marriage,' which begged the question why the separate institution of civil partnership was secured for same-sex couples if it was materially the same as heterosexual marriage. The result being a legislative refusal to redefine marriage

29 A Lloyd 'Zanele Muholi's new work mourns and celebrates South African queer lives' http://africasacountry.com/2014/03/zanele-muholis-new-work-mournsand-celebrates-south-african-queer-lives/ (accessed 19 October 2016).

$30 M$ van Zyl 'Are same-sex marriages un-African? Same-sex relationships and belonging in post-apartheid South Africa' (2011) 67 Journal of Social Issues 376.

31 Civil Union Act 17 of 2006.

32 Minister of Home Affairs v Fourie 20063 BCLR 355 (CC).

33 Marriage Act 25 of 1961.

34 J Bernard-Naudé 'Sexual minority freedom and the heteronormative in South Africa' in Vilhena et al (eds) Transformative Constitutionalism: Comparing the Apex Courts of Brazil, India and South Africa (2013) 322.

35 Civil Union Bill 26 of 2006. 
as directed by the Constitutional Court and a denial of the same status as that of married heterosexual couples to same-sex couples. The legal recognition of same-sex couples created by the Bill was clearly inferior, or less-than, as an addition to the creation of a new institution; section 12 provided that upon registration in a separate register, same-sex couples would receive a registration certificate and not a marriage certificate. The Bill understandably came under pressure and was redrafted as a proposal that would later become the Civil Union Act as it stands today. The Civil Union Act is problematic because its enactment did not amend or repeal the 1961 Marriage Act, it allows heterosexual couples a choice between concluding a civil union through the Act or a marriage through the Marriage Act and it contains a provision that allows a state marriage officer to refuse to solemnise a same-sex civil union. ${ }^{36}$

\subsection{Queer violence, state silence}

Some survivors have said that their male attackers told them they'd make them pregnant; that they'd prove to them they're not a man, they're a woman. It threatens and destabilises their male power.

Zanele Muholi ${ }^{37}$

Expressing our identities can be affirming and a great source of pleasure and pride. When the visible expression of that identity, however, does not conform to the gender expectation of our culture, it becomes dangerous and a source of fear. Within the cultural context of competing heteropatriarchies, gender and sexual nonconformity challenges and poses a threat to hegemonic masculinities - something that even a progressive Constitution would have trouble overcoming. 38

In July of 2013 the research unit of the Parliament of the Republic of South Africa released a paper written by Jennifer Thorpe entitled 'Corrective rape', hate crimes, and the law in South Africa' which sought to provide a background to the prevailing issue of violence against Lesbian women, to show that such violence falls within the scope of hate crimes and assess the failure of the Department of Justice and Constitutional Development to present a draft bill addressing such violence. 'Corrective or curative rape' is a term given to the heterosexual rape of Lesbian and Bisexual women under the erroneous belief that the rape will have a 'healing' effect on these

36 Bernard-Naudé (n 34 above) 330-334.

37 Lloyd (n 29 above). Muholi describes her interactions with Black Lesbians from various townships who have survived 'curative or corrective' rape and finds that it is not a coincidence that most of the women who experience these attacks are masculine presenting or 'butch.'

38 Van Zyl (n 30 above) 371. 
women and will return them to their natural 'straight' orientation and the rape of Transgender women to punish them for their transition. The definition of the crime has been expanded to include all members of the LGBTQI+ community. The perpetrators of this crime often make statements such as 'we will teach you a lesson' or 'show you how to be a real woman,' which is a clear indication of the belief that these identities are unnatural and immoral and that the crime is thus committed with a prejudice or hatred towards the victims. Prevailing narratives surrounding 'corrective or curative' rapes fail to acknowledge that poor Black women, living in townships and rural areas are most likely to be victims of this crime and that these women are made more vulnerable by the failure of the state to adequately provide for their socio-economic needs. In November 2010, the Minister of Justice made an announcement that the Department of Justice and Constitutional Development had already prepared a draft bill to address these crimes. In May 2011, the Department made a further announcement that they would establish a National Task Team to address 'corrective rape' after immense public outcry. Despite these promises, as of July 2013, no such draft bill had been presented and violence continues to increase.

Lea Mwambene and Maudri Wheal argue that it is necessary to define 'corrective or curative rape' as a crime in order to secure protection for those affected by it, who are mostly Black Lesbians. The authors say that of the numerous rapes, assaults and murders of Queer women as reported by non-governmental organisation, only two cases have successfully secured convictions and both were unreported. The first case, is that of 31-year-old Eudy Simelane, a well-known soccer star who played for Banyana-Banyana and out Lesbian, who was gang-raped, beaten and murdered on 28 April 2008 in the township of Kwa-Thema near Johannesburg. Her naked body was found discarded near a stream. Additionally, she was robbed of her cell phone, trainers and cash. She was stabbed 25 times in her face, abdomen and legs and died from abdominal wounds. Four suspects appeared in trial at the Delmas High Court in 2009, but only two were convicted and sentenced to life imprisonment and 32 years imprisonment respectively, whilst the other two were acquitted. The relevance of her sexual orientation to her killers' motives was ruled out by the court in the early stages of the trial. The judge stated that her sexual orientation had no bearing on the case despite outrage from various LGBTQI+ rights activists and organisations. ${ }^{39}$ The second case, is that of 19-year-old masculine-presenting openly Lesbian Zoliswa Nkonyana who was brutally stabbed, kicked, stoned and beaten to death just meters away from her home in the township of

39 L Mwambene \& $M$ Wheal 'Realisation or oversight of a constitutional mandate? Corrective rape of black African lesbians in South Africa' (2015) 15 African Human Rights Law Journal 74-76. 
Khayelitsha in Cape Town on 4 February $2006 .{ }^{40}$ Although she was not raped, her case is significant to the author because her killers explicitly stated that they had killed her because of her sexual orientation. Their conviction was a long awaited triumph under the LGBTQI+ rights activist community. Her case was one of the longest in South African history as it was postponed fifty times. Zoliswa's case was heard in the Khayelitsha Magistrate's Court in 2011 and sentencing was set for 1 February 2012, almost six years later, to the day. Four of the nine accused were convicted on 7 October 2011. The sentencing was significant for the protection of victims as the magistrate said that it should serve as a deterrent to the accused as well as to the community at large by sending a message that such crimes would not be tolerated. However, the court did consider retribution and rehabilitation and held that:

The court has a duty to enforce the ideology that violent intolerance of difference, whether it be based on race, whether it be based on sex, whether it be based on religion, [whether it be based on sexual orientation], it will not go unpunished and it will not go rewarded. ${ }^{41}$

The bold finding of the court in the Zoliswa case is a departure from the stance taken in the Eudy Simelane case and appears to be a step towards greater protection for Black Queer women in townships and rural areas, but it will prove difficult to implement. 'Corrective or curative' rape is currently not recognised as a separate category of crime and thus when a rape is reported no distinction is made as to the motive of the perpetrator and when motive is considered it only comes into consideration during sentencing as an aggravating factor. ${ }^{42}$ The author argues that 'corrective or curative' rape should be considered a hate crime and not just a crime of rape and that, until that happens, South Africa will have failed to fulfil its constitutional mandate of protecting the victims.

40 Case number RCB216/06 (unreported).

41 Mwambene \& Wheal (n 39 above) 80.

42 Mwambene \& Wheal (n 39 above) 77-81. 


\section{$4 \quad$ Ubuntu and feminism as responses to oppression}

A person with ubuntu is open and available to others, affirming of others, does not feel threatened that others are able and good, for he or she has the proper selfassurance that comes from knowing that he or she belongs in a greater whole and is diminished when others are humiliated or diminished, when others are torture or oppressed, or treated as if they were less than who they are.

Archbishop Desmond Tutu ${ }^{43}$

In this part of this article I wish to consider what theoretical conception of and what practical approaches to the identity of Black Queer women are necessary in order to liberate and resist against the powers of oppression that haunt such an identity, taking into account the role that culture plays in African communities and the transformative potential of ubuntu to unite us. Muholi believes that 'we are in a time when we don't know what is African anymore. Who is African and who decides what is African? We, as Black communities, have not had our histories documented properly' and for her documenting Black Queers is a contestation of the belief that we are unAfrican. ${ }^{44}$

The law turns sexualities and gender identities into a space which the state can control and dominate. Apartheid regulations that criminalised homosexuality and sodomy and the criminalisation of prostitution are an example of the control and domination of men and women who do not conform to sexual hegemonic powers and imposed modes of identity, morality and behaviour. ${ }^{45}$ Western theories on sexualities and gender identities dominate discourses because most of these theories and perspectives were generated by the West. To uncritically apply these theories in non-West contexts would not create culture-specific knowledge and would be limiting.

The problem that colonial language presents is that it is permeated with Western ideology and traditions. ${ }^{46}$ This problem practically presents itself when trying to define African concepts such as ubuntu. Yvonne Mokgoro posits that, to attempt to define the African notion of ubuntu with any definitive precision in a foreign language would be unattainable and rather takes the approach of

D Tutu No future without forgiveness (1999) 34-35.

Lloyd (n 29 above).

S Tamale 'Introduction' in S Tamale (ed) African sexualities: A reader (2011) 2-3. Tamale (n 45 above) 4. 
putting forward views that relate to the concept. Mokgoro's view of ubuntu can be described as:

a philosophy of life, which in its most fundamental sense represents personhood, humanity, humaneness and morality; a metaphor that describes group solidarity is central to the survival of communities where such communities with a scarcity of resources, where the fundamental belief is that motho ke motho ba batho ba bangwe/umuntu ngumuntu ngabantu which, literally translated, means a person can only be a person through others. In other words the individual's whole existence is relative to that of the group: this is manifested in antiindividualistic conduct towards the survival of the group if the individual is to survive. It is a basically humanistic orientation towards fellow beings. ${ }^{47}$

The important social values of ubuntu make the meaning of the concept clearer. These values are: group solidarity, conformity, compassion, respect, human dignity, humanist orientation and collective unity. These values are shared with an ethic of care, the practical use of which may help facilitate a better understanding of ubuntu as forming the basis of our relationships.

\subsection{An ethic of care as a demand of ubuntu}

Life is a gift from our ancestors that we borrow from our children/ Blessed are those guided by words moulded by the light of their vision/ Life is a gift from our ancestors that we borrow from our children/ Blessed are those guided by words woven with a ribbon of rhythm.

Lebogang Mashile 48

Ubuntu is an ethical notion that underpins the meaning of dignity as ethically and legally significant, as they are both central to an ethical ideal of what it means to be a human being. Ubuntu demands respect and the recognition of the dignity of others, the impact and value of which are significant in areas of law pertaining to socio-economic rights such as constitutional development. ${ }^{49}$ Jonathan Herring argues that caring is an essential dimension of human existence, it is central to our humanity. ${ }^{50}$ To Herring, our identities, values and well-being as humans are intertwined with our relationships and the obligations that flow from them. He suggests that the values of freedom, justice and autonomy need to be utilised to allow and support caring. Herring

47 Y Mokgoro 'Ubuntu and the law in South Africa' (1998) 1 The Potchefstroom Electronic Law Journal 16.

48 Extract from poem Every Child, My Child featured in L Mashile In a ribbon of rhythm (2005).

49 D Cornell \& N Muvangua Ubuntu and the law: African ideals and post-apartheid jurisprudence (2012) xi.

50 J Herring Caring and the law (2013) 2. 
refers to an ethic of care which challenges the way legal rights and duties are commonly understood. He suggests that an ethic of care requires the rethinking of how we understand the role of law and the nature of rights. The core value of an ethics of care is care; it is a move away from an individualised view of rights to a norm of interlocking mutually dependent relationships. ${ }^{51}$ One of the aims of an ethic of care is to bring practices of care to the forefront of ethical, social and legal analysis. ${ }^{52}$ An ethic of care can be utilised in law in ways that extend beyond the court. The law can be used to facilitate and promote caring relationships between citizens and can also be used to create legal, political and social systems structured around an ethic of care which can require state intervention to facilitate caring relationships; this would undoubtedly benefit any attempt to end sexist oppression. ${ }^{53}$ It appears than an ethic of care is in line with the basis of socio-political human relationships under the concept of ubuntu.

\subsection{Ubuntu and feminism}

O, ye daughters of Africa, awake! Awake! Arise! No longer sleep nor slumber, but distinguish yourselves. Show forth to the world that ye are endowed with noble and exalted faculties.

Maria Stewart ${ }^{54}$

Cornell and van Marle offer ubuntu feminism as an answer to the paradoxes presented by Western feminism concerning identity politics. A fair question to ask is where our differences fall within ubuntu and how, if at all, they colour our socio-political human relationships, and whether essentialism is a legitimate concern. It is important to note that ubuntu is concerned with the moral obligations that underlie our relationships as people who were, are and will always be connected to each other. ${ }^{55}$ The philosophy of ubuntu articulates a revised humanism that inherently challenges anti-Black racism. Through an ubuntu framework ethical feminism's foundational definition is the struggle against racism and all other forms of oppression that render people less than human. By understanding that to be human means to be intertwined with others, our point of departure cannot be individualism. That does not, however, mean a complete sacrifice of the self and assimilation into

51 Herring (n 50 above) 46-47.

52 Herring (n 50 above) 81.

53 Herring (n 50 above) 84-85.

54 Excerpt from an address given in 1831 by the first African-American woman to give public lectures to a mixed audience - MW Stewart America's first black woman political writer; Essays and speeches (1987) 30.

55 D Cornell \& K van Marle 'Ubuntu feminism: Tentative reflections' (2015) 36 Verbum et Ecclesia 3-4. 
the collective. Rather, it denotes a joint commitment to an imagined future in which the triumphs of the individual mark a triumph for all others. In this sense it becomes clearer that what is meant by the ubuntu expression 'people are people through other people,' is that the self is relational and that the way in which the individual becomes identified as distinguished from the others is through their support. Revolutionary ubuntu does not run the risk of either essentialism or allowing our differences to divide us. On the contrary, it requires a new understanding of belonging together that acknowledges our sameness and also the inequality and oppression experienced by so many of us, and requires us to commit ourselves to achieving equality and justice for all others. Ubuntu also forms a site of resistance because it is not rigid; it is dynamic, continuous and constantly in search of justice. ${ }^{56}$

In addition to an ethic of care, the author believes the philosophy of ubuntu feminism aligns with what bell hooks [sic] calls an ethic of love. An ethic of love calls for a collective transformation of society and an end to politics of domination even when we have suffered no domination or oppression ourselves because of the vested interest we have in the struggle of others against oppression and exploitation. ${ }^{57}$ To choose an ethic of love is to denounce a culture of domination and commit oneself to enhancing the collective good; it means 'communion with the world beyond the self, the tribe, the race, the nation ... a constant invitation for personal expansion and growth'; it means a commitment to the service of others; it means making a move towards freedom and acting in ways that liberate ourselves and others. ${ }^{58}$

\section{Conclusion}

Because each had discovered years before that they were neither white not male, and that all freedom and triumph was forbidden to them, they had set about creating something else to be.

Toni Morrison 59

The aim of this article was to consider an ubuntu feminist framework as the most suitable means of bringing about social and political justice for Black Queer women as it takes into account the interconnectedness of African communities. South Africa was built on a foundation of racism, human rights violations and gender inequality that can only be redressed by moving away from an essentialist and

56 Cornell \& van Marle (n 55 above) 5-6.

57 b hooks Outlaw culture: Resisting representations (2006) 244.

58 hooks (n 57 above) 246-250.

59 T Morrison Sula (1974) 52. 
universal definition of 'woman', as the political and economic status of Black women has provided and continues to provide us with lived experiences that differ significantly from those of white women, as members of the subordinate and dominant group respectively. It was found that, following the social structure of the patriarchy, antiracism movements focus on Black men. Due to the economic, social and political power created by white domination, it was found that feminist movements' focus on middle-class white women and, that LGBTQI+ movements focus on middle-class cisgender white men. The author found that Black Queer women occupy cultural spaces that do not adhere to Western ideals of gender liberation and thus that Black Queer women are under-represented in social justice movements and lack the protection and support provided by these projects.

Black Queer identities hold so many possibilities for transformation of sexual minority freedom and gender equality in that they challenge current categories of identities and put us to the task of imagining new ways of caring for each other and being human together. Butler suggests that the term Queer should not have a fixed meaning, rather: ${ }^{60}$

If the term is to be a site of collective contestations, the point of departure for a set of historical reflections and future imaginings, it will have to remain that which is, in the present, never fully owned, but always and only redeployed, twisted, queered from a prior usage and direction of urgent and expanding political purposes. This also means that it will doubtless have to be yielded in favour of terms that do that political work more effectively

The concept of ubuntu and the term Queer engage each other in that neither is static, neither has been perfected, both are perpetually under construction, and both look to the commonality of human experience as the ground on which marginality and oppression can be challenged and interrogated and yet simultaneously the grounds on which such marginality and oppression reveal themselves as questionable. Queer exists as a testament to past, present and future self-identification beyond the restrictions of binary invocations and ubuntu is a testament to the endless and transformative potential of our being human together and the possibility of a re-imagined South African jurisprudence.

Zanele Muholi's photographs are a testament to the ingenuity of the Queer spirit. They represent resistance against heteropatriarchal domination and resilience in the face of exclusion from our families and communities. But most of all, they represent the joy and love we carry in our hearts and share with each other. We are bound to each other by so much more than shared exclusion and oppression. We are 
bound by a mutual love for each other and the desire to see one another thrive. Ubuntu feminism can bring about the radical political transformation that Black Queer women require through its commitment to end sexist exploitation and anti-Black racism and unshackle society from systems, structures and institutions that fail to acknowledge the fullness of our humanity. 